\title{
EFEKTIFITAS PROGRAM PENGEMBANGAN USAHA AGRIBISNIS PERDESAAN PADA GAPOKTAN BUNGA NILAM DI DESA SIMAU KECAMATAN GALELA KABUPATEN HALMAHERA UTARA
}

\author{
Yonete Maya Tupamahu \\ Staf Pengajar Faperta UMMU-Ternate,e-mail: ymtup@yahoo.co.id
}

\begin{abstract}
ABSTRAK
Program PUAP akan berjalan secara efektif bilamana pelaksana di tingkat kecamatan dan desa menjalankan tugasnya secara efektif. Tujuan penelitian yaitu untuk mengetahui apakah pelaksanaan Program PUAP pada Gapoktan Bunga Nilam di Desa Simau efektif atau tidak. Indikator penelitian ini adalah pelaksanaan tugas: (1) Pengurus Gapoktan; (2) Penyuluh Pendamping; (3) Penyelia Mitra Tani. Data dianalisis secara deskriptif menggunakan sistem pemberian skor. Penentuan skor menggunakan skala Likert, skor terbesar adalah tiga (3) untuk jawaban selalu, dua (2) untuk jawaban sering, dan satu (1) untuk jawaban tidak pernah. Berdasarkan perolehan skor dari responden, lalu ditentukan rentang skala atau selang untuk menentukan efektifitas pelaksanaan Program PUAP. Penilaian tanggapan responden terhadap efektifitas pelaksanaan PUAP dibagi ke dalam tiga kategori, yaitu efektif, cukup efektif, dan tidak efektif. Hasil penelitian menunjukkan bahwa pelaksanaan program Pengembangan Usaha Agribisnis Pedesaan (PUAP) pada Gapoktan Bunga Nilam di Desa Simau tidak efektif. Hal ini disebabkan pelaksana program PUAP di tingkat kecamatan dan desa yang menjalankan tugasnya hanya Pengurus Gapoktan, sedangkan Penyuluh Pendamping dan Penyelia Mitra Tani tidaklah melaksanakan tugasnya. Disarankan perlu dilakukan evaluasi mengenai kompetensi petugas pelaksana PUAP sehingga pelaksana di lapangan harus diganti. Serta perlu dilakukan pendampingan secara kontinu oleh petugas pendamping Gapoktan, sehingga efektifitas pelaksanaan program PUAP dapat tercapai.
\end{abstract}

Kata Kunci: Efektifitas, Pengembangan Usaha Agribisnis Perdesaan (PUAP), Gapoktan

\section{PENDAHULUAN}

\subsection{Latar Belakang}

Pengembangan Usaha Agribisnis

Perdesaan atau PUAP merupakan salah satu program pemerintah khususnya Departemen Pertanian. Program PUAP dilaksanakan oleh petani (pemilik dana atau penggarap), buruh tani, pengolahan hasil dan pemasaran hasil pertanian, terutama untuk keluarga miskin di Desa/Kelurahan, melalui Gapoktan sebagai lembaga yang dimiliki dan dikelola oleh petani (Anonim, 2010).

Gapoktan sebagai pelaksana PUAP merupakan penggabungan dari beberapa kelompok tani dalam satu kawasan desa.
Tujuan penggabungan kelompok menjadi Gapoktan dalam PERMENTAN Nomor 273/Kpts/OT.160/4/2007 adalah untuk menggalang kepentingan bersama secara kooperatif agar kelompok tani lebih berdaya guna dan berhasil guna, dalam penyediaan sarana produksi pertanian, permodalan, peningkatan atau perluasan usaha tani di sektor hulu dan hilir, pemasaran serta kerjasama dalam peningkatan posisi tawar (Anonim, 2007).

Salah satu Gapoktan yang mendapat bantuan PUAP adalah Gapoktan Bunga Nilam di Desa Simau, Kecamatan Galela, Halmahera Utara. Gapoktan Bunga Nilam terbentuk pada 
tahun 2003 dengan jumlah anggota sebanyak 55 orang, terdiri dari Kelompok Tani Totemo Maloha (27 orang) dan Kelompok Tani Toma Gafur (28 orang).

Gapoktan Bunga Nilam mulanya menanam komoditi jagung dan sayur-sayuran, namun mengalami penurunan produksi dari waktu ke waktu. Hal ini disebabkan petani selama ini tidak melakukan pergiliran tanaman ataupun tumpangsari, sehingga memungkinkan menurunnya kesuburan tanah dan adanya serangan hama dan penyakit tanaman. Penurunan produksi pada akhirnya menyebabkan menurunnya pendapatan petani. Pada tahun 2011, ada bantuan pemerintah melalui program Pengembangan Usaha Agribisnis Perdesaan atau PUAP untuk tanaman kedelai, sehingga petani beralih ke tanaman kedelai apalagi ditunjang tersedianya pasar untuk hasil produksi.

Gapoktan melaksanakan tugasnya didampingi oleh Penyuluh Pendamping dan Penyelia Mitra Tani serta berpijak pada Pedoman Umum PUAP. Bilamana pelaksana PUAP di Desa Simau seperti pengurus Gapoktan Bunga Nilam, Penyuluh Pendamping dan Penyelia Mitra Tani melaksanakan tugasnya dengan efektif maka secara umum dikatakan pelaksanaan program PUAP pun akan efektif. Rifanto (1989) menjelaskan efektifitas adalah seberapa baik pekerjaan yang dilakukan, sejauh mana orang menghasilkan keluaran sesuai dengan yang diharapkan. Ini berarti bahwa apabila suatu pekerjan dapat diselesaikan sesuai dengan perencanaan, baik dalam bentuk waktu, biaya maupun mutunya, maka dikatakan efektif. Dengan kata lain, efektifitas merupakan proses pencapaian suatu tujuan yang telah ditetapkan sebelumnya, dan suatu kegiatan dapat dikatakan efektif bila kegiatan itu telah mencapai tujuannya.

Berdasarkan uraian diatas, maka penting dilakukan penelitian tentang pelaksanaan program PUAP pada Gapoktan Bunga Nilam apakah efektif ataukah tidak melalui analisis efektifitas.

\subsection{Tujuan Penelitian}

Untuk mengetahui apakah pelaksanaan Program PUAP pada Gapoktan Bunga Nilam di Desa Simau efektif atau tidak.

\section{METODE PENELITIAN}

2.1. Metode Penentuan Lokasi

Penelitian ini dilakukan di Desa Simau Kecamatan Galela Kabupaten Halmahera Utara pada bulan Juni - Juli 2012. Penentuan lokasi secara sengaja (purposive), alasannya pengusahaan tanaman kedelai oleh Gapoktan Bunga Nilam mendapat bantuan Program Pengembangan Usaha Agribisnis Pedesaan (PUAP).

\subsection{Jenis dan Sumber Data}

Data penelitian ini bersumber dari data primer dan data sekunder. Data primer diperoleh melalui observasi dan wawancara dengan petani Gapoktan Bunga Nilam penerima dana PUAP, serta pihak lain yang berhubungan langsung dengan penelitian ini. Sedangkan data sekunder, diperoleh dari dinas terkait yang berhubungan dengan penelitian ini.

\subsection{Metode Penentuan Responden}

Penentuan banyaknya petani kedelai yang dijadikan responden menggunakan metode sensus (census sampling). Gapoktan Bunga Nilam terdiri dari 2 Kelompok Tani, yaitu Totemo Maloha dan Toma Gafur. Petani penerima dana PUAP pada Kelompok Tani Totemo Maloha sebanyak 12 orang, dan Kelompok Tani Toma sebanyak 20 orang. Rianse dan Abdi (2009) menyatakan pengambilan sampel jenis sensus dicirikan oleh pengambilan seluruh populasi sebagai sampel, penelitian, apabila jumlah populasi kurang dari 50 orang. Maka total sampel penelitian ini sebanyak 32 orang.

\subsection{Metode Analisis}

Program PUAP akan berjalan secara efektif bilamana pelaksana di tingkat kecamatan dan desa menjalankan tugasnya sebagaimana tertuang pada Pedoman Umum PUAP. Indikator penelitian ini adalah pelaksanaan tugas: (1) Pengurus Gapoktan; (2) Penyuluh Pendamping;

(3) Penyelia Mitra Tani. Efektifitas pelaksanaan Program PUAP berdasarkan tanggapan petani sebagai sasaran PUAP terhadap ketiga pelaksana.

Data diperolah dari wawancara dengan petani, lalu data tersebut disajikan dalam bentuk tabulasi silang yang kemudian 


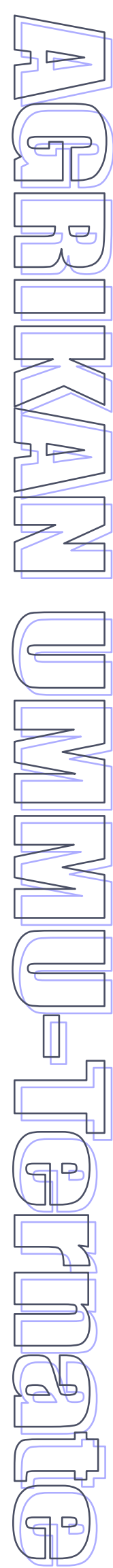

dianalisis secara deskriptif. Analisisnya menggunakan sistem pemberian skor yang kemudian diuraikan secara deskriptif. Penentuan skor menggunakan skala Likert. Pengukurannya dilakukan dengan menghadapkan responden petani pada beberapa pertanyaan sesuai indikator di atas, kemudian responden diminta untuk memberikan jawaban atau tanggapan yang terdiri dari tiga tingkatan dalam skala tersebut. Jawaban-jawaban tersebut, diberikan skor 1-3 dengan pertimbangan skor terbesar adalah tiga (3) untuk jawaban selalu, dua (2) untuk jawaban sering, dan satu (1) untuk jawaban tidak pernah.

Berdasarkan perolehan skor dari responden, lalu ditentukan rentang skala atau selang untuk menentukan efektifitas pelaksanaan Program PUAP. Umar (2005) menjelaskan selang diperoleh dari selisih total skor tertinggi yang mungkin dengan total skor minimal yang mungkin dibagi dengan jumlah kategori jawaban. Tahap selanjutnya yaitu menentukan skor efektifitas pelaksanaan program PUAP, dengan cara membagi tiga skor di antara nilai skor terendah atau minimal sampai total nilai tertinggi, hingga akan diperoleh tiga selang efektifitas.

Penilaian tanggapan responden terhadap efektifitas pelaksanaan PUAP dibagi ke dalam tiga kategori, yaitu efektif, cukup efektif, dan tidak efektif. Misalnya pada indikator tugas Pengurus Gapoktan ada empat parameter pertanyaan, maka nilai skor yang diperoleh antara 128-384. Nilai skor 128 didapat dari hasil perkalian skor terendah (1) dengan jumlah parameter (pertanyaan) yaitu empat dan dengan jumlah responden (32 resoponden), atau dapat ditulis ( $1 \times 4 \times 32=128)$, sedangkan skor 384 diperoleh dari hasil perkalian skor tertinggi (3) dengan jumlah parameter (pertanyaan) yaitu empat dan dengan jumlah responden (32) atau dapat ditulis $(3 \times 4 \times 32=$ 384).

Penentuan selang untuk setiap tingkatan penilaian dilakukan dengan cara pengurangan antara nilai skor tertinggi dengan nilai skor terendah lalu hasilnya dibagi dengan kategori penilaian, atau dapat ditulis dengan $\frac{384-128}{3}=85,3 \approx 85$. Nilai 85 merupakan selang untuk setiap tingkatan penilaian, maka dapat ditentukan rentang selang skala tiap kategori penilaian. Hal yang sama dilakukan untuk kategori indikator lainnya yaitu Penyuluh Pendamping dan Penyelia Mitra Tani.

\section{HASIL DAN PEMBAHASAN}

3.1. Efektifitas Pelaksanaan Program PUAP melalui Indikator Pengurus Gapoktan

Untuk mengetahui pelaksanaan Program PUAP apakah efektif atau tidak efektif maka dikaji melalui indikator pelaksanaan tugas Pengurus Gapoktan, sebagai berikut:

1. Melakukan penyusunan Rancangan Usaha Baru (RUB) Usahatani Kedelai

2. Melaksanakan pertemuan rutin dengan anggota Gapoktan.

3. Menyalurkan dan memantau penggunaan dana PUAP.

4. Menyusun laporan pelaksanaan PUAP

Adapun kategori efektifitas pelaksanaan Program PUAP melalui indikator tugas pengurus Gapoktan sebagai berikut :

- Efektif :300-385

- Cukup efektif : 214-299

- Tidak efektif : 128-213

Hasil penelitian dapat dilihat pada Tabel 1.

Tabel 1. Jawaban Responden Tentang Pelaksanaan Tugas Pengurus Gapoktan

\begin{tabular}{ccccc}
\hline Skala Jawaban & $\begin{array}{c}\text { Bobot } \\
\text { (B) }\end{array}$ & $\begin{array}{c}\text { Frekuensi } \\
\text { (F) }\end{array}$ & Nilai (BxF) & Skor \\
\hline Selalu & 3 & 0 & 0 & 0 \\
Sering & 2 & 128 & 256 & 256 \\
Tidak Pernah & 1 & 0 & 0 & 0 \\
\hline Jumlah & & & & 256 \\
\hline
\end{tabular}

Hasil penelitian pada Tabel 1 menunjukkan bahwa keseluruhan responden menyatakan bahwa pengurus Gapoktan sering menjalankan tugasnya sebagaimana tercantum pada indikator tersebut di atas. Jumlah skor indikator tugas pelaksanan pengurus Gapoktan 
adalah sebesar 256, dan berada pada kategori Cukup Efektif. Sehingga ketika pengurus Gapoktan sering melaksanakan tugasnya maka pelaksanaan Program PUAP di Gapoktan Bunga Nilam pun cukup efektif.

\subsection{Efektifitas Pelaksanaan Program PUAP} melalui Indikator Tugas Penyuluh Pendamping

Untuk mengetahui pelaksanaan Program PUAP apakah efektif atau tidak efektif maka dikaji melalui indikator pelaksanaan tugas Penyuluh Pendamping sebagai berikut:

1. Mengidentifikasikan potensi ekonomi desa yang berbasis usahatani

2. Melakukan bimbingan teknis Usaha Agribisnis Pedesaan termasuk pemasaran hasil usaha

3. Membantu petani atau Gapoktan untuk memecahkan permasalahan usaha serta mendampingi Gapoktan selam proses penumbuhan kelembagaan

4. Melakukan pelatihan usaha agribisnis dan usaha ekonomi produktif sesuai potensi desa.

5. Membantu memberikan fasilitas kemudahan akses terhadap sarana produksi, teknologi dan pasar

6. Memberikan bimbingan teknis dalam pemanfaatan dana PUAP

7. Membantu Gapoktan membuat laporan perkembangan PUAP

Adapun kategori efektifitas pelaksanaan Program PUAP melalui indikator tugas Penyuluh Pendamping sebagai berikut :

\begin{tabular}{|c|c|}
\hline - Efektif & : 524-673 \\
\hline Cukup efektif & : 374-52 \\
\hline Tidak efektif & : 224 \\
\hline
\end{tabular}

Hasil penelitian tersaji pada Tabel 2.

Tabel 2. Jawaban Responden Tentang Pelaksanaan Tugas Penyuluh Pendamping

\begin{tabular}{ccccc}
\hline Skala Jawaban & $\begin{array}{c}\text { Bobot } \\
\text { (B) }\end{array}$ & $\begin{array}{c}\text { Frekuensi } \\
(\mathrm{F})\end{array}$ & Nilai (BxF) & Jumlah Skor \\
\hline Selalu & 3 & 0 & 0 & 0 \\
Sering & 2 & 0 & 0 & 0 \\
Tidak Pernah & 1 & 224 & 224 & 224 \\
\hline Total & \multicolumn{5}{r}{} \\
\hline
\end{tabular}

Tabel 2 menunjukkan bahwa semua responden menjawab bahwa petugas Penyuluh Pendamping tidak pernah menjalankan tugasnya sebagaimana tercantum pada indikator tersebut diatas. Jumlah skor efektifitas melalui tugas indikator tugas Penyuluh Pendamping adalah sebesar 224. Berarti bila petugas Penyuluh Pendamping tidak pernah menjalankan tugasnya maka pelaksanaan Program PUAP akan tidak efektif.

\subsection{Efektifitas Pelaksanaan Program PUAP melalui Indikator Tugas Penyelia Mitra Tani}

Untuk mengetahui pelaksanaan Program PUAP melalui indikator tugas Penyelia Mitra tani apakah efektif atau tidak efektif maka dikaji melalui indikator pelaksanaan tugas Penyelia Mitra Tani sebagai berikut:

1. Melakukan supervisi kepada Penyuluh Pendamping dan Gapoktan

2. Melaksanakan pertemuan regular dengan Penyuluh Pendamping dan Gapoktan
3. Menyusun sistem pemanfaatan dana PUAP

4. Melakukan verifikasi awal terhadap RUB dan dokumen administrasi lainnya

5. Membuat laporan perkembangan pelaksanaan PUAP

Adapun kategori efektifitas pelaksanaan Program PUAP melalui indikator tugas Penyelia Mitra Tani sebagai berikut :

$\begin{array}{lll}\text { - } & \text { Efektif } & : 376-483 \\ \text { - Cukup Efektif } & : 268-375 \\ \text { - } & \text { Tidak efektif } & : 160-267\end{array}$

Hasil penelitian tersaji pada Tabel 3, Tabel 3 menunjukkan bahwa semua responden menjawab bahwa petugas Penyelia Mitra Tani tidak pernah menjalankan tugasnya sebagaimana tercantum pada indikator tersebut diatas. Jumlah skor efektifitas melalui indikator Tugas Penyelia Mitra Tani adalah sebesar 160. Berarti ketika petugas Penyelia Mitra Tani tidak pernah menjalankan tugasnya, maka pelaksanaan Program PUAP akan tidak efektif. 
Tabel 3. Jawaban Responden Tentang Pelaksanaan Tugas Penyelia Mitra Tani

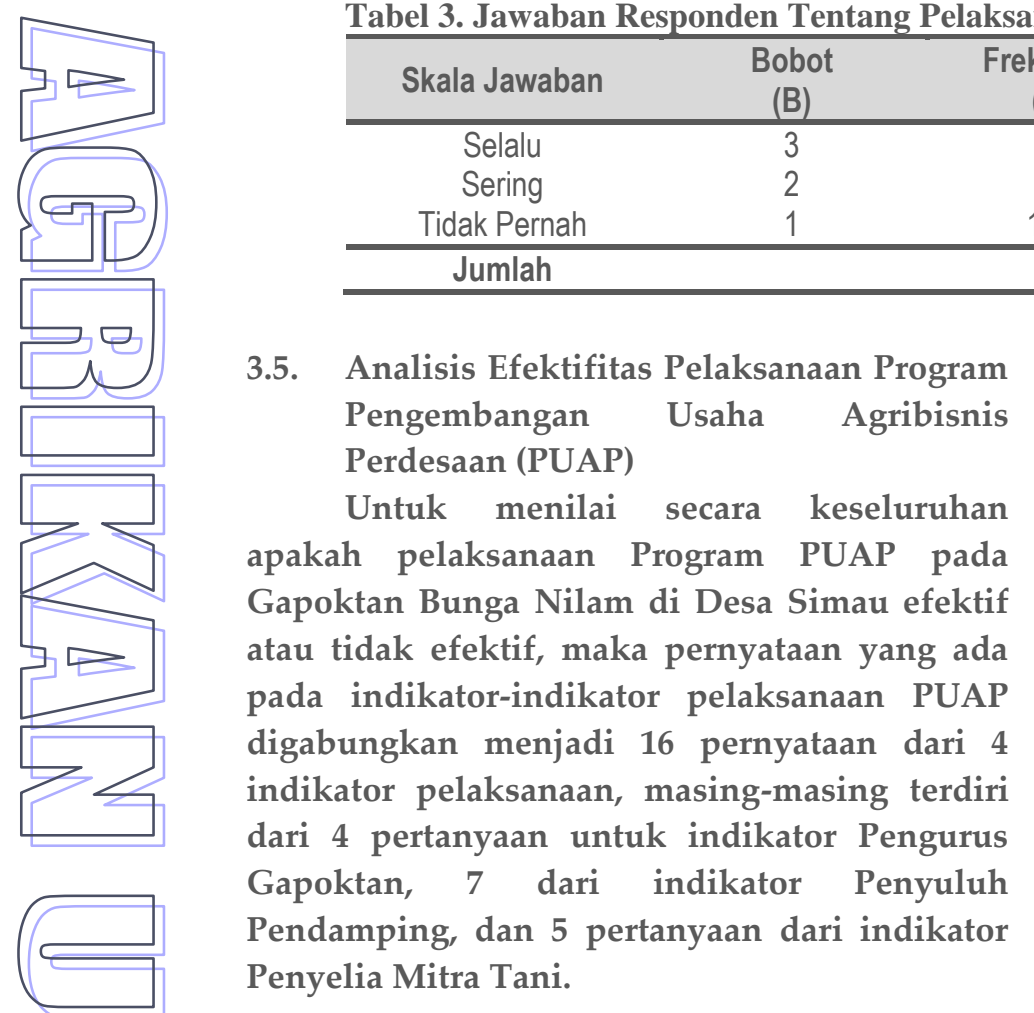

\begin{tabular}{ccc}
$\begin{array}{cc}\text { kuensi } \\
(\mathrm{F})\end{array}$ & Nilai $(\mathrm{BxF})$ & Skor \\
\hline 0 & 0 & 0 \\
0 & 0 & 0 \\
160 & 160 & 160 \\
\hline
\end{tabular}

Adapun kategori efektifitas pelaksanaan Program PUAP untuk Gapoktan Bunga Nilam di Desa Simau :

- Efektif :1196-1537

- Cukup Efektif : 854-1195

- Tidak efektif : 576-853

Hasil penelitian tersaji pada Tabel 4, Tabel 4 menunjukkan bahwa jumlah total skor sebesar 640 dan berada pada kategori Tidak Efektif. Berarti pelaksanaan Program PUAP untuk usahatani kedelai pada Gapoktan Bunga Nilam di Desa Simau tidak efektif.

Tabel 4. Efektifitas Pelaksanaan Program PUAP Untuk Usahatani Kedelai di Desa Simau.

\begin{tabular}{ccccc}
\hline Kategori & Bobot (B) & Frekuensi(F) & Nilai (BxF) & Skor \\
\hline Efektif & 3 & 0 & 0 & 0 \\
Cukup Efektif & 2 & 128 & 256 & 256 \\
Tidak Efektif & 1 & 384 & 384 & 384 \\
\hline Jumlah Total & & & 640 \\
\hline
\end{tabular}

\section{KESIMPULAN DAN SARAN}

4.1. Kesimpulan

Berdasarkan pembahasan diatas, disimpulkan bahwa pelaksanaan program Pengembangan Usaha Agribisnis Pedesaan (PUAP) pada Gapoktan Bunga Nilam di Desa Simau tidak efektif. Hal ini disebabkan pelaksana program PUAP di tingkat kecamatan dan desa yang menjalankan tugasnya hanya Pengurus Gapoktan, sedangkan Penyuluh Pendamping dan Penyelia Mitra Tani tidaklah melaksanakan tugasnya.

\subsection{Saran}

Saran yang dikemukakan terkait dengan hasil penelitian adalah sebagai berikut :

1. Perlu dilakukan evaluasi mengenai kompetensi petugas pelaksana PUAP sehingga pelaksana di lapangan harus diganti.

2. Perlu dilakukan pendampingan secara kontinu oleh petugas pendamping Gapoktan, sehingga efektifitas pelaksanaan program PUAP dapat tercapai.

\section{DAFTAR PUSTAKA}

Anonim, 2007. Modul Training of Trainers (TOT) Pengembangan Usaha Agribisnis Perdesaan (PUAP), Pusat Pengembangan Pelatihan Pertanian, Badan Pengembangan Sumber Daya Manusia, Departemen Pertanian. Jakarta.

Anonim, 2010. Pedoman Umum PUAP, Departemen Pertanian, Jakarta.

Rianse, Usman dan Abdi, 2009. Metodologi Penelitian Sosial dan Ekonomi dalam Teori dan Aplikasi. Edisi I, Alfabeta, Bandung.

Umar, Husein, 2005. Metode Pelitian Untuk Skripsi dan Tesis Bisnis, Raja Garafindo Persada, Jakarta. 